\title{
PENGARUH KADAR METAKAOLIN TERHADAP KUAT TEKAN PADA HIGH STRENGTH SELF COMPACTING CONCRETE (HSSCC) USIA 14 DAN 28 HARI
}

\author{
Muhammad Imam Mustawa Kamal ${ }^{1)}$, Wibowo' ${ }^{2)}$ Endah Safitri ${ }^{3)}$ \\ 1) Mahasiswa Program Studi Teknik Sipil, Fakultas Teknik, Universitas Sebelas Maret Surakarta \\ 2) 3) Pengajar Program Studi Teknik Sipil, Fakultas Teknik, Universitas Sebelas Maret Surakarta \\ Jalan Ir. Sutami 36A, Surakarta, 57126; Tlp 0271-647069, Email: muhimammk@gmail.com
}

\begin{abstract}
High strength self-compacting concrete (HSSCC) is one of the concrete innovations that have a high quality standard. This type of concrete has a high compressive strength and can compact without tools. Metakaolin is used in this research as a cement replacement to increase the quality of HSSCC and to reduce it's weaknesses. Metakaolin is made from kaolin which is a white powder measuring 0,5 to 5 micron that then heated at $500-900^{\circ} \mathrm{C}$. Parameters that are studied in this research are setting time, workability, and the compressive strength of HSSCC. Setting time are measured by vicat test to understand the effect of Metakaolin replacement on HSSCC. Workability are measured by slump-flow table test, l-box test, v-funnel test and v-funnel $T_{5 \text { minute }}$ test. Compressive strength performed on 14 and 28 days old with compressive testing machine. Based on this research, Metakaolin increases compressive strength of concrete linearly. Metakaolin slows down concrete setting time and reduces early compressive strength of concrete at 14 days old. Workability decreases as more Metakaolin is used. Only Metakaolin addition at 5\% and 7,5\% fulfills fillingability and passingability parameter based on EFNARC 2002.
\end{abstract}

Keywords: high strength self compacting concrete, metakaolin, compressive strength, setting time, workability

\begin{abstract}
Abstrak
Beton mutu tinggi memadat mandiri adalah salah satu inovasi beton yang memiliki standar kualitas yang tinggi. Beton jenis ini memiliki kuat tekan yang tinggi dan dapat memadat tanpa bantuan alat. Metakaolin digunakan sebagai bahan pengganti semen untuk meningkatkan kualitas beton tersebut dan mengurangi kelemahannya. Metakaolin terbuat dari kaolin yang merupakan bubuk putih berukuran 0,5 hingga 5 mikron yang kemudian dipanaskan pada suhu $500-900^{\circ} \mathrm{C}$. Parameter yang dipelajari dalam penelitian ini adalah setting time, workability, dan kuat tekan HSSCC. Setting time diukur dengan uji vicat untuk memahami efek penambahan Metakaolin pada HSSCC. Workability diukur dengan slump-flow table test, l-box test, v-funnel test and v-funnel $T_{5 \text { minute }}$ test. Kekuatan tekan dilakukan pada umur 14 dan 28 hari dengan compressive testing machine. Berdasarkan hasil penelitian, Metakaolin meningkatkan kuat tekan beton secara linier. Metakaolin memperlambat waktu ikat semen dan menurunkan kuat tekan awal beton umur 14 hari. Semakin banyak Metakaolin yang digunakan, workability semakin menurun. Hanya penambahan metakaolin dengan kadar 5\% dan 7,5\% yang memenuhi parameter fillingability dan passingability berdasarkan EFNARC 2002.
\end{abstract}

Kata Kunci : beton mutu tinggi memadat mandiri, metakaolin, kuat tekan, waktu ikat, workability

\section{PENDAHULUAN}

Beton merupakan bahan yang sering digunakan dalam konstruksi bangunan. Kebutuhan pembangunan yang semakin pesat melahirkan inovasi-inovasi baru pada beton yang meningkatkan kualitas dan mutu beton. Beton mutu tinggi memadat mandiri atau bigh strength self-compacting concrete (HSSCC) adalah salah satu inovasi beton yang memiliki standar kualitas yang tinggi. Beton jenis ini memiliki kuat tekan yang tinggi dan dapat memadat tanpa bantuan alat. Beton mutu tinggi cenderung memiliki kekentalan yang tinggi sehingga penggunaan superplasticizer diwajibkan untuk meningkatkan workability dan mempertahankan parameter SCC.

Metakaolin adalah pozzolan yang digunakan sebagai bahan pengganti semen untuk meningkatkan kualitas beton HSSCC dan mengurangi kelemahan yang terdapat pada beton konvensional. Metakaolin berasal dari kaolin yang dipanaskan pada suhu $500-900^{\circ} \mathrm{C}$, berbentuk serbuk berukuran 0,5 sampai 5 mikron dan berwarna putih. Walaupun di Indonesia penggunaannya masih langka, di negara lain, metakaolin menjadi alternatif dari silica fume karena lebih murah dan dapat mencapai kuat tekan seperti silica fume.

Penggunaan metakaolin pada beton normal menurut Srivastava et al (2012) dapat membuat pasta beton lebih homogen karena terjadi reaksi antara metakaolin yang merupakan pozolan dengan kalsium hidrat hasil hidrasi semen. Metakaolin merupakan pozolan yang sangat reaktif sehingga berguna meningkatkan kualitas beton dengan meningkatkan kuat tekan dan mengurangi waktu setting beton. Semakin banyak jumlah penambahan metakaolin pada beton, maka workability menurun yang disebabkan oleh luas permukaan metakaolin lebih besar dibandingkan dengan semen. Hal ini dapat diatasi dengan penambahan superplasticizerer sehingga parameter SCC beton dapat dijaga. 
Berdasarkan hasil penelitian Emir Ahmad (2017) yang menggunakan benda uji berbentuk silinder dengan diameter $15 \mathrm{~cm}$ dan tinggi $30 \mathrm{~cm}$, penambahan kadar metakaolin sebesar 10\% merupakan kadar terbaik yang memenuhi semua persyaratan pengujian beton segar, yaitu memenuhi semua sifat dari beton SCC. Sementara itu, kuat tekan maksimum terdapat pada beton dengan kadar metakaolin sebesar 60\%, yaitu 49,99 MPa untuk beton umur 14 hari dan 61,09 MPa untuk beton umur 28 hari.

\section{METODE}

\section{Benda Uji}

Pada penilitian kali ini, benda uji yang digunakan berbentuk silinder dengan ukuran diameter 7,5cm dan tinggi $15 \mathrm{~cm}$.

\section{Rancang Campur (Mix Design)}

Kadar bahan beton yang digunakan pada tiap $1 \mathrm{~m}^{3}$ dapat dilihat pada Tabel 1. di bawah ini

Tabel 1. Rancang Campur HSSCC - MK per $1 \mathrm{~m}^{3}$

\begin{tabular}{|c|c|c|c|c|c|c|}
\hline Kode. & $\begin{array}{l}\text { Ag. Kasar } \\
\left(\mathrm{Kg} / \mathrm{m}^{3}\right)\end{array}$ & $\begin{array}{c}\text { Ag. Halus } \\
\left(\mathrm{Kg} / \mathrm{m}^{3}\right)\end{array}$ & $\begin{array}{l}\text { Semen } \\
\left(\mathrm{Kg} / \mathrm{m}^{3}\right)\end{array}$ & $\begin{array}{c}\text { Metakaolin } \\
\left(\mathrm{Kg} / \mathrm{m}^{3}\right)\end{array}$ & $\begin{array}{c}\text { Air } \\
\left(1 \mathrm{lt} / \mathrm{m}^{3}\right)\end{array}$ & $\begin{array}{c}\text { Superplasticizer } \\
\left(1 \mathrm{lt} / \mathrm{m}^{3}\right)\end{array}$ \\
\hline HSSCC MK $0 \%$ & 801,25 & 916,23 & 550,00 & 0 & 165,00 & 4,13 \\
\hline HSSCC MK 5\% & 801,25 & 911,57 & 522,50 & 27,5 & 165,00 & 4,13 \\
\hline HSSCC MK 7,5\% & 801,25 & 909,20 & 508,75 & 41,25 & 165,00 & 4,13 \\
\hline HSSCC MK 10\% & 801,25 & 906,82 & 495,00 & 55,00 & 165,00 & 4,13 \\
\hline HSSCC MK $12,5 \%$ & 801,25 & 904,45 & 481,25 & 68,75 & 165,00 & 4,13 \\
\hline
\end{tabular}

\section{Pengujian Beton Segar}

Pengujian beton SCC ini dilakukan sesuai dengan standar EFNARC (2002) yaitu Slump Flow Test, L-Box Test dan $V$-Funnel Test. Tinjauan utama dari pengujian ini adalah terhadap parameter beton SCC yaitu passingability, fillingability dan segregation resistance.

\section{Pengujian Beton Keras}

Pengujian beton keras dilakukan dalam bentuk pengujian kuat tekan beton dengan menggunakan alat Universal Testing Machine (UTM) dengan umur uji 14 hari dan 28 hari.

\section{HASIL DAN PEMBAHASAN}

Hasil Pengujian Beton Segar

Berikut ini merupakan hasil pengujian beton segar yang dapat dilihat dalam Tabel 2.

Tabel 2. Hasil Pengujian Beton Segar

\begin{tabular}{|c|c|c|c|c|c|c|c|c|c|c|c|c|}
\hline \multicolumn{5}{|c|}{ Flow Table Test } & \multicolumn{4}{|c|}{ L-Box Test } & \multicolumn{4}{|c|}{$V$-Funnel Test } \\
\hline Kode & $\begin{array}{c}\mathrm{d}_{\text {rerata }} \\
(\mathrm{mm})\end{array}$ & $\begin{array}{c}\text { Syarat } \\
(\mathrm{mm})\end{array}$ & $\begin{array}{c}\mathrm{T}_{500} \\
(\mathrm{~s})\end{array}$ & $\begin{array}{c}\text { Syarat } \\
\text { (s) }\end{array}$ & $\mathrm{h}_{2} / \mathrm{h}_{1}$ & $\begin{array}{l}\text { Syarat } \\
\mathrm{h}_{2} / \mathrm{h}_{1}\end{array}$ & $\begin{array}{c}\mathrm{T}_{200} \\
(\mathrm{~s})\end{array}$ & $\begin{array}{c}\mathrm{T}_{400} \\
(\mathrm{~s})\end{array}$ & $\begin{array}{l}\text { Waktu } \\
\text { Aliran } \\
\text { Awal / } \\
\mathrm{T}_{\text {awal }}(\mathrm{s})\end{array}$ & $\begin{array}{c}\text { Syarat } \\
\mathrm{T}_{\text {awal }} \\
(\mathrm{s})\end{array}$ & $\begin{array}{c}\text { Waktu } \\
\text { Aliran } 5 \\
\text { menit / } \\
\mathrm{T}_{5 \min }(\mathrm{s})\end{array}$ & $\begin{array}{c}\text { Syarat } \\
\mathrm{T}_{5 \min } \\
(\mathrm{s})\end{array}$ \\
\hline $\begin{array}{l}\text { HSSCC } \\
\text { MK } 0 \%\end{array}$ & 665 & $650-800$ & 3,1 & $2-5$ & 1 & $0,8-1,0$ & 1 & 2,7 & 8,00 & $8-12$ & 12,21 & +3 \\
\hline $\begin{array}{l}\text { HSSCC } \\
\text { MK 5\% }\end{array}$ & 705 & $650-800$ & 2,1 & $2-5$ & 0,88 & $0,8-1,0$ & 1,2 & 2 & 13,01 & $8-12$ & 18,47 & +3 \\
\hline $\begin{array}{l}\text { HSSCC } \\
\text { MK } 7,5 \%\end{array}$ & 680 & $650-800$ & 3,6 & $2-5$ & 0,82 & $0,8-1,0$ & 1,6 & 4,5 & 14,18 & $8-12$ & 29,32 & +3 \\
\hline $\begin{array}{l}\text { HSSCC } \\
\text { MK } 10 \%\end{array}$ & 660 & $650-800$ & 4,5 & $2-5$ & 0,63 & $0,8-1,0$ & 2,3 & 6,9 & 29,11 & $8-12$ & 42,68 & +3 \\
\hline $\begin{array}{l}\text { HSSCC } \\
\text { MK 12,5\% }\end{array}$ & 655 & $650-800$ & 6,2 & $2-5$ & 0,55 & $0,8-1,0$ & 2,7 & 7,4 & 39,71 & $8-12$ & 49,34 & +3 \\
\hline
\end{tabular}


Hasil Flow Table Test

Berikut ini merupakan grafik hasil pengujian flow table yang dapat dilihat pada Gambar 1 dan Gambar 2.

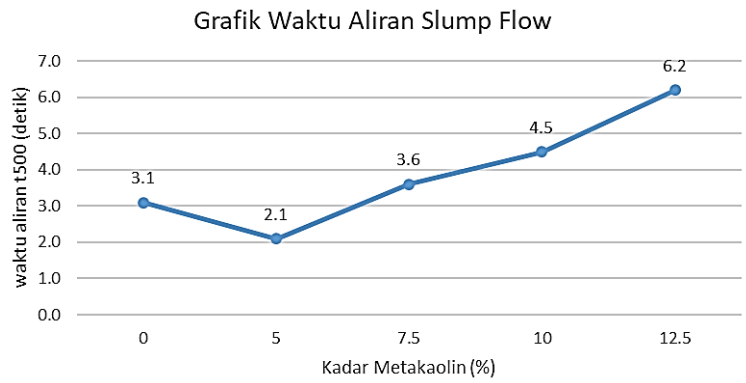

Gambar 1. Grafik Diameter Sebaran Flow Table Test dengan Kadar Metakaolin

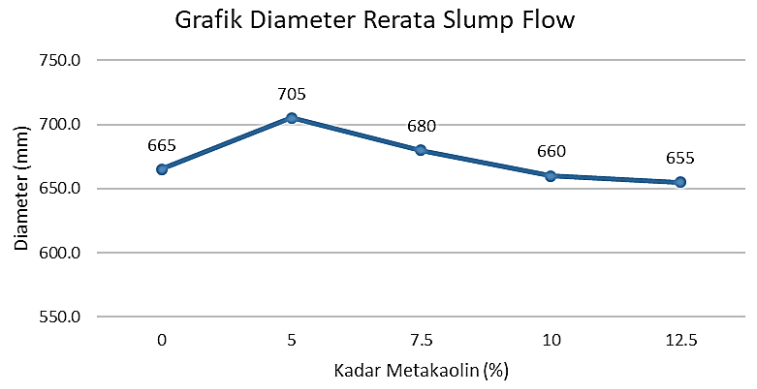

Gambar 2. Grafik $\mathrm{T}_{500}$ pada Flow Table Test dengan Kadar Metakaolin

Berdasarkan Gambar 1 sampai dengan Gambar 2 yang menunjukkan pengaruh kadar metakaolin terhadap diameter sebaran dan waktu t 500 beton, semakin tinggi kadar metakaolin yang dicampurkan maka diameter sebaran dan waktu $\mathrm{t}_{500}$ akan semakin meningkat pula. Beton dengan variasi kadar metakaolin $5 \%$ memiliki diameter sebaran tertinggi sebesar $705 \mathrm{~mm}$ dengan waktu $\mathrm{t}_{500}$ sebesar 2,0 detik.

\section{Hasil L-Box Test}

\section{L-Box Test Results}

Berikut ini merupakan grafik hasil pengujian L-Box yang dapat dilihat pada Gambar 3 dan Gambar 4.

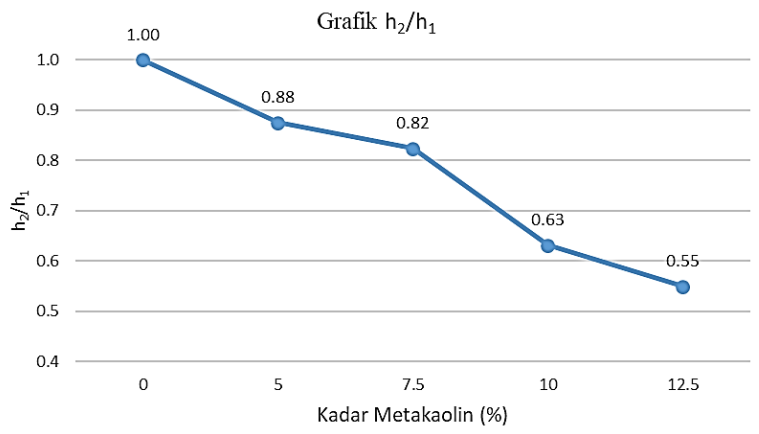

Gambar 3. Grafik $\mathrm{h}_{2} / \mathrm{h}_{1}$ pada L-Box Test dengan Kadar Metakaolin

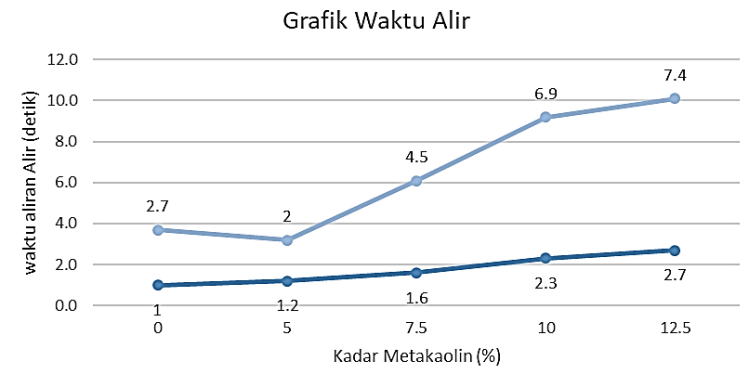

$\leadsto \mathrm{t} 200 \leadsto \mathrm{t} 400$ 
Gambar 4. Grafik $\mathrm{T}_{200}$ dan $\mathrm{T}_{400}$ pada L-Box Test dengan Kadar Metakaolin

Menurut data yang disajikan pada Gambar 3 dapat dilihat bahwa $h_{2} / h_{1}$ mengalami penurunan yang berarti semakin banyak penambahan metakaolin maka parameter passingability beton mengalami penurunan. Pada beton segar tanpa bahan tambah, nilai $\mathrm{h}_{2} / \mathrm{h}_{1}$ adalah 1 . Kemudian menurun semakin tinggi penambahan metakaolin yaitu pada kadar $5 \%$ dan 7,5\%dengan nilai $\mathrm{h}_{2} / \mathrm{h}_{1}$,, 88 dan 0,82 secara berturut-turut. Pada penambahan kadar $10 \%$ dan 12,5\%, diameter sebaran tidak memenuhi syarat SCC karena kurang dari 0,8, yaitu 0,63 dan 0,55.

Sedangkan menurut data yang disajikan pada Gambar 4 dapat dilihat bahwa waktu alir beton segar pada L-box meningkat semakin banyaknya kadar metakaolin yang digunakan. Pada beton segar tanpa penambahan metakaolin, $\mathrm{t}_{200 \mathrm{~mm}}$ dan $\mathrm{t}_{400 \mathrm{~mm}}$ adalah 5,64 detik dan 8 detik. Pada penambahan kadar 5\% metakaolin, $\mathrm{t}_{200 \mathrm{~mm}}$ dan $\mathrm{t}_{400 \mathrm{~mm}}$ menurun menjadi 1,2 detik dan 2,0 detik kemudian meningkat seiring dengan penambahan kadar metakaolin. Pada penambahan kadar 7,5\% metakaolin, $\mathrm{t}_{200 \mathrm{~mm}}$ dan $\mathrm{t}_{400 \mathrm{~mm}}$ adalah 1,6 detik dan 4,5 detik. Pada penambahan kadar 10\% metakaolin, $\mathrm{t}_{200} \mathrm{~mm}$ dan $\mathrm{t}_{400 \mathrm{~mm}}$ adalah 2,3 detik dan 6,9 detik. Pada penambahan kadar 12,5\% metakaolin, $\mathrm{t}_{200 \mathrm{~mm}}$ dan $\mathrm{t}_{400 \mathrm{~mm}}$ adalah 2,7 detik dan 7,4 detik.

Semakin tinggi kadar metakaolin yang digunakan sebagai pengganti semen, maka passing ratio atau $h_{2} / h_{1}$ menurun diakibatkan oleh metakaolin yang mengikat lebih banyak air sehingga beton menjadi lebih kohesif. Hal ini terbantu oleh penambahan superplasticizer yang dapat meningkatkan workability beton segar sehingga dapat memberikan beton dengan bahan tambah metakaolin passingability yang lebih baik.

\section{Hasil V-Funnel Test}

Berikut ini merupakan grafik hasil pengujian $V$-Funnel yang dapat dilihat pada Gambar 5.

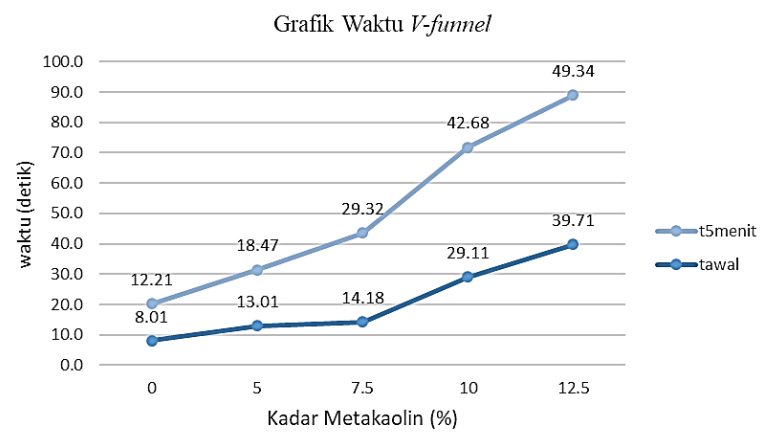

Gambar 5. Grafik Waktu Aliran pada V-funnel Test dengan Kadar Metakaolin

Dari Gambar 5 dapat dilihat bahwa semakin tinggi kadar metakaolin maka semakin tinggi waktu yang diperlukan untuk mengalir. Beton segar tanpa penambahan metakaolin memiliki waktu alir 8 detik yang memenuhi persyaratan self compacting concrete yaitu 6-12 detik. Pada penambahan metakaolin 5\%, 7,5\%,10\%, dan 12,5\% didapatkan waktu alir 5,45 detik, 13,01 detik, 14,18 detik, 29,11 detik dan 39,71 detik secara berturut-turut. Dapat dilihat juga bahwa semakin tinggi kadar metakaolin maka semakin tinggi waktu yang diperlukan untuk mengalir. Beton segar tanpa penambahan metakaolin memiliki waktu alir 12,21 detik yang memenuhi persyaratan self compacting concrete yaitu maksimal +3 detik dari $V$-funnel test biasa. Pada penambahan metakaolin 5\%,7,5\%,10\%, dan 12,5\% didapatkan waktu alir 18,47 detik, 29,32 detik, 42,68 detik, dan 49,34 detik secara berturut-turut.

\section{Hasil Pengujian Kuat Tekan}

Berikut ini merupakan hasil pengujian kuat tekan beton yang tercantum pada Tabel 3

Tabel 3. Hasil Uji Kuat Tekan Umur 14 Hari dan 28 Hari

\begin{tabular}{lcc}
\hline \multicolumn{1}{c}{ Kode } & $\begin{array}{c}\text { Kuat Tekan } \\
\text { 14 Hari (MPa) }\end{array}$ & $\begin{array}{c}\text { Kuat Tekan } \\
\text { 28 Hari (MPa) }\end{array}$ \\
\hline HSSCC MK 0\% & 36,58 & 43,02 \\
\hline HSSCC MK 5\% & 29,55 & 41,06 \\
\hline HSSCC MK 7,5\% & 30.58 & 42,75 \\
\hline HSSCC MK 10\% & 33,39 & 44,55 \\
\hline HSSCC MK 12,5\% & 35,93 & 46,36 \\
\hline
\end{tabular}




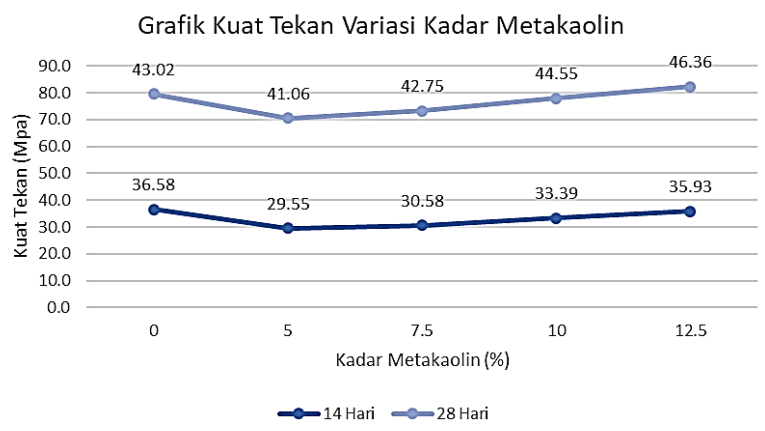

Gambar 6. Grafik Kuat Tekan Beton d 7,5 cm x $15 \mathrm{~cm}$ dengan Kadar Metakaolin

Menurut data yang disajikan pada Gambar 6 dapat dilihat bahwa metakaolin meningkatkan kuat tekan beton. Pada beton tanpa bahan tambah metakaolin didapatkan kuat tekan 36,58 MPa pada 14 hari dan 43,02 MPa pada 28 hari. Pada beton umur 14 hari, penambahan metakaolin menghasilkan kuat tekan 29,55 MPa, 30,58 MPa, dan 33,39 MPa pada kadar 5\%, 7,5\%, dan 10\% secara berturut-turut. Pada kadar 12,5\%, kuat tekan beton meningkat hingga 35,93 MPa. Pada beton umur 28 hari, penambahan metakaolin 5\% menghasilkan kuat tekan lebih rendah dari beton acuan yaitu 41,06 MPa. Kuat tekan naik pada penambahan kadar 7,5\%, 10\% dan 12,5\% yaitu 42,75 MPa, 44,55 MPa dan 46,36 MPa secara berturut-turut.

Penambahan metakaolin pada umur 14 hari tidak meningkatkan kuat tekan awal beton dikarenakan oleh campuran beton high strength self compacting concrete (HSSCC) yang sangat padat sehingga terdapat ruang kosong yang sangat kecil antara semen dan agregat. Padatnya campuran ini menyebabkan metakaolin terhambat dalam mengisi ruang kosong tersebut. Filler effect yang tidak sempurna ini menyebabkan kuat tekan awal yang rendah seperti yang diteliti oleh Norhasri (2016). Penyebab lain kemungkinan dengan adanya penambahan bahan tambah yang mengganggu senyawa pada semen yang berperan untuk meningkatkan kuat tekan awal beton yaitu senyawa $C_{3} S$ dan $C_{3} A$. Reaksi pozolanik pada beton umur 14 hari dan kadar pozolan yang rendah belum dapat bereaksi dengan $\mathrm{C}-\mathrm{H}$ secara optimal seperti yang terjadi pada beton umur 28 hari sesuai dengan penelitian El-Din tahun 2017. Beton dengan penambahan kadar metakaolin 12,5\% pada umur 14 hari memiliki kuat tekan lebih tinggi dari beton acuan. Pada penambahan kadar metakaolin 12,5\% ini, reaksi pozolanik lebih terlihat daripada kadar yang lebih rendah dalam meningkatkan kuat tekan beton.

Meningkatnya kuat tekan beton dengan penambahan metakaolin disebabkan oleh reaksi pozolanik. Reaksi pozolanik terjadi ketika metakaolin yang merupakan bahan pozolan bereaksi dengan senyawa kalsium hidrat $\left(\mathrm{Ca}(\mathrm{OH})_{2}\right) \cdot \mathrm{Ca}(\mathrm{OH})_{2}$ atau biasa disebut $\mathrm{C}-\mathrm{H}$ adalah senyawa yang dihasilkan oleh hidrasi semen dan terbentuk dari $25 \%$ dari massa pasta semen yang terhidrasi.

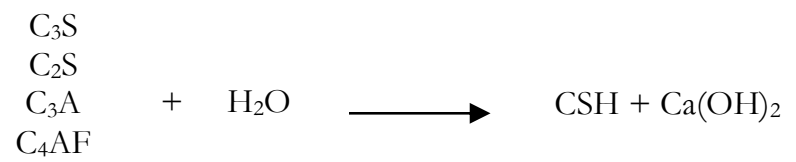

C-H biasanya bereaksi dengan $\mathrm{CO}_{2}$ yang kemudian menjadi gas lalu menguap meninggalkan rongga kosong pada beton yang mengakibatkan rendahnya kuat tekan beton.

$$
\mathrm{Ca}(\mathrm{OH})_{2}+\mathrm{CO}_{2} \rightarrow \mathrm{CaCO}_{3}+\mathrm{H}_{2} \mathrm{O}
$$

Metakaolin berperan mengikat senyawa $\mathrm{C}-\mathrm{H}$ ini dalam reaksi pozolanik. Reaksi pozolanik mengubah $\mathrm{C}-\mathrm{H}$ menjadi C-S-H tambahan yang dapat meningkatkan kuat tekan beton melalui reaksi kimia di bawah ini.

$$
\mathrm{MK}\left[\mathrm{Al}_{2} \mathrm{Si}_{2} \mathrm{O}_{7}\right]+\mathrm{CH}+\mathrm{H} \rightarrow \mathrm{C}-\mathrm{S}-\mathrm{H}, \mathrm{C}_{4} \mathrm{AH}_{13}, \mathrm{C}_{3} \mathrm{AH}_{6}, \mathrm{C}_{2} \mathrm{ASH}_{8}
$$

Filler effect adalah proses pengisian rongga kosong yang terdapat dalam campuran beton. Metakaolin yang merupakan bahan tambah pada penelitian ini berperan dalam mengisi rongga kosong dalam campuran beton. Porositas beton adalah salah satu aspek yang mendapatkan keuntungan dengan adanya filler effect ini. Dengan adanya penambahan metakaolin, terjadi peningkatan kepadatan campuran beton atau aggregate packing dikarenakan butiran metakaolin yang sangat kecil daripada semen. Metakaolin juga berperan sebagai penutup pori saat terjadi reaksi pozolanik yang menyebabkan bertambahnya senyawa C-S-H disekitar partikel metakaolin. 
Beton umur 14 hari memiliki kuat tekan yang lebih rendah daripada beton acuan. Campuran beton high strength self compacting concrete (HSSCC) yang sangat padat menyebabkan adanya ruang kosong yang sangat kecil antara semen dan agregat. Padatnya campuran beton ini mengakibatkan efek retarding pada metakaolin dalam mengisi rongga yang kosong tersebut sehingga mengurangi kekuatan awal beton seperti yang telah diteliti oleh Norhasri pada tahun 2016.

Penambahan metakaolin meningkatkan kepadatan beton yang meningkatkan kekuatan beton salah satunya melalui ball bearing effect. Ball bearing effect adalah dimana partikel metakaolin yang lebih kecil dari semen bertindak sebagai pelicin antara seluruh komponen penyusun beton seperti semen, pasir, dan kerikil. Metakaolin melicinkan permukan komponen - komponen penyusun beton yang mengakibatkan bergesernya komponen pada bagian atas campuran beton ke bawah campuran dengan bantuan gravitasi. Dengan bergesernya komponen penyusun beton maka campuran beton akan semakin padat yang akibatnya meningkatkan kekuatan beton itu sendiri.

\section{KESIMPULAN}

Dari data hasil pengujian, analisis data, dan pembahasan beton mutu tinggi memadat mandiri dengan variasi komposisi metakaolin, dapat ditarik kesimpulan sebagai berikut:

a. Berdasarkan hasil pengujian SCC pada beton segar, tidak ada kadar penggantian semen dengan metakaolin yang memenuhi seluruh parameter SCC (fillingability, passingability, dan segregation resistance).

b. Penambahan variasi metakaolin pada campuran beton mutu tinggi memadat mandiri meningkatkan nilai kuat tekan beton silinder d 7,5 cm x $15 \mathrm{~cm}$ pada umur 14 hari menghasilkan kuat tekan 29,55 MPa, 30,58 MPa, $33,39 \mathrm{MPa}$ dan 35,93 MPa pada kadar 5\%, 7,5\%,10\% dan 12,5\% secara berturut-turut. Sedangakan pada umur 28 hari menghasilkan kuat tekan 41,06 MPa, 42,75 MPa, 44,55 MPa dan 46,36 MPa pada kadar 5\%, 7,5\%, 10\% dan $12,5 \%$ secara berturut-turut.

c. Kuat tekan beton maksimum d 7,5 cm x $15 \mathrm{~cm}$ umur 14 hari terjadi pada kadar metakaolin sebesar $12,5 \%$ sedangkan pada umur 28 hari terjadi pada kadar metakaolin sebesar 12,5\%.

d. Tidak ada persentase kadar metakaolin yang digunakan yang memenuhi parameter beton mutu tinggi dan beton memadat mandiri pada beton silinder dengan d 7,5 $\mathrm{cm}$ x $15 \mathrm{~cm}$ umur pengujian 14 dan 28 hari.

\section{REFERENSI}

As'ad, Solihin. 2012. "Beton Memadat Mandiri”. Harian JOGLOSEMAR, 12 Agustus 2012.

Dharmawan, E.A., Wibowo, dan Mediyanto, A., 2017. "Kajian Pengaruh Variasi Kompposisi Metakaolin Terbadap Parameter Beton Memadat Mandiri dan Kuat Tekan Beton Mutu Tinggi”. Skripsi, Program Studi Teknik Sipil Fakultas Teknik Universitas Sebelas Maret.

EFNARC. 2002. "Specification and Guidelines for Self-Compacting Concrete".

El-Din, H.K.S., et al. 2017. "Mechanical performance of high strength concrete made from high volume of Metakaolin and hybrid fibers". Structural Engineering Department, Faculty of Engineering, Zagazig University, Egypt.

Herbudiman, B., Siregar, S.E. 2013. "Kajian Interval Rasio Air-Powder Beton Self-Compacting Terkait Kinerja Kekuatan dan Flow”. Jurusan Teknik Sipil Institut Teknologi Nasional (Itenas) Bandung.

Norhasri, M.S.M., et al. 2016. "Inclusion of nano metakaolin as additive in ultra high performance concrete (UHPC)". Faculty of Civil Engineering, Universiti Teknologi MARA (UiTM), Shah Alam, Selangor, Malaysia.

Yonnes, F., Warman, H., dan Khadavi. 2013. "Pengaruh Pemakaian Superplasticizer (Sika Viscocrete 1003) Dalam Rancangan Beton Mutu Tinggi”. Jurusan Teknik Sipil, Fakultas Teknik Sipil Dan Perencanaan, Universitas Bung Hatta Padang. 